\title{
Csk Regulates Blood Pressure by Controlling the Synthetic Pathways of Aldosterone
}

\author{
Sung-Moon Kim; Ji-One Kang, PhD; Ji Eun Lim, PhD; \\ Sue-Yun Hwang, PhD; Bermseok Oh, PhD
}

\begin{abstract}
Background: Blood pressure is regulated by a network of diverse physiological pathways. The C-terminal Src kinase (CSK) locus (15q24) is associated with blood pressure in various ethnic groups. It was recently reported that Csk insufficiency increases blood pressure through Src. The mechanisms of hypertension in $\mathrm{Csk}^{+/-}$mice are examined further in this study.
\end{abstract}

\begin{abstract}
Methods and Results: To identify a causal component responsible for hypertension in Csk ${ }^{+-}$, the heart rate was measured by electrocardiogram and plasma volume by Evans blue dilution. Plasma volume increased in Csk ${ }^{+/-}$compared with wild-types, while the heart rate did not change. Plasma sodium and aldosterone levels rose consistently in Csk ${ }^{+/-}$vs. wild-types, and spironolactone, a mineralocorticoid receptor antagonist, reduced blood pressure. The amounts of Sgk1 and Na+/K+-ATPase (NKA) increased in the kidney of $\mathrm{Csk}^{+/-}$compared with wild-types. It was also found that Cyp11b2 (aldosterone synthase) was upregulated in the adrenal glands of $\mathrm{Csk}^{+-}$, and that Csk was enriched in the zona glomerulosa of adrenals, the major site of aldosterone production in the normal mouse.
\end{abstract}

Conclusions: The results of the present study identify a physiological pathway by which blood pressure is regulated, in which the insufficiency of Csk induces aldosterone production with zonal specificity in the adrenal glands, increasing sodium reabsorption and plasma volume and thus resulting in hypertension.

Key Words: Adrenal gland; Aldosterone; Blood pressure; C-terminal Src kinase (CSK); Plasma volume

B lood pressure is a complex trait that is regulated by a network of physiological pathways that involve the modulation of heart rate, vascular tone, and blood volume. ${ }^{1}$ Short-term regulation of blood pressure is attained via the effects of sympathetic/parasympathetic activation on vascular tone and cardiac contractility through the sensing of baroreceptors in large arteries, whereas longterm regulation occurs through the effects of the reninangiotensin-aldosterone system (RAAS) on the kidney in controlling blood volume. ${ }^{2}$ Despite their classical definition, short-term regulatory mechanisms are not easily dissected from long-term mechanisms, because the autonomic nervous system and RAAS permeate common target tissues and often relay signals through shared signaling pathways.

Genetic research, including genome-wide association studies (GWASs), has identified approximately 116 singlenucleotide polymorphisms (SNPs) and rare mutations that contribute to the genetic architecture of blood pressure and hypertension. ${ }^{3-7}$ It is now evident that hypertension is a polygenic trait, wherein rare syndromes of hypertension represent extreme cases, because most hypertensive cases are not explained by a mutation in a single gene. ${ }^{3}$ Further, the finding of genes that cause monogenic syndromes highlights the significant functions of the kidney and adrenal gland in regulating blood pressure.,3 Specifically, $10 \%$ of all monogenic forms of hypertension are estimated to have primary aldosteronism, suggesting that the homeostatic maintenance of aldosterone levels and the effect of aldosterone on kidney function are pivotal in keeping blood pressure within the normal range. ${ }^{3}$

Despite the increase in the discoveries of SNPs that are associated with blood pressure, few cases have revealed an association between a genetic variation and the causal pathway that leads to hypertension. The most notable studies have reported a variant (rs13333226) in the promoter region of the uromodulin gene $(U M O D),{ }^{8}$ a SNP in the promoter (rs3918226) near the endothelial nitric oxide synthase (eNOS) gene, ${ }^{9,10}$ a SNP (rs5068) in the 3' untranslated region of $N P P A$, the gene that encodes for atrial natriuretic peptide (ANP), ${ }^{11,12}$ and a SNP (rs17249754)

Received January 26, 2017; revised manuscript received June 7, 2017; accepted June 20, 2017; released online July 20 , 2017 Time for primary review: 28 days

Department of Animal Biotechnology, Graduate School of Future Convergence Technology (S.-M.K.), Department of Chemical Engineering, College of Engineering (S.-Y.H.), Hankyong National University, Ansung-Si, Gyeonggi-Do; Department of Biochemistry and Molecular Biology, School of Medicine, Kyung Hee University, Seoul (J.-O.K., J.E.L., B.O.), Korea

The first two authors contributed equally to this work (S.-M.K., J.-O.K.).

The last two authors contributed equally to this work as corresponding authors (S.-Y.H., B.O.).

Mailing address: Bermseok Oh, PhD, Department of Biochemistry and Molecular Biology, School of Medicine, Kyung Hee University, 26 Kyungheedae-ro, Dongdaemun-gu, Seoul 02447, Korea. E-mail: ohbs@khu.ac.kr

ISSN-1346-9843 All rights are reserved to the Japanese Circulation Society. For permissions, please e-mail: cj@j-circ.or.jp 
near the plasma membrane calcium-transporting ATPase 1 gene $(A T P 2 B 1) .13,14$

The $15 \mathrm{q} 24$ locus is one of many that have been identified by blood pressure GWASs in Asians and Europeans, ${ }^{11,15,16}$ and has been confirmed by GWASs in Japanese, Koreans, and Europeans..$^{17} \mathrm{We}$ recently reported that this locus harbors C-terminal Src kinase (CSK), a causative gene that is associated with changes in blood pressure and regulates blood pressure through Src. ${ }^{18}$

Csk represses the activity of Src family tyrosine kinases (Src, Fyn, and Lyn) by phosphorylating their negative regulatory tyrosine in vitro, $\mathbf{1 9 , 2 0}$ and functions as their negative regulator in vivo. ${ }^{21,22}$ Mice embryos that are null for Csk die at embryonic day 9-10 and exhibit several developmental defects, including abnormal vascularization. .1,23 $^{21}$ Csk is also associated with blood pressure, as supported by a study of spontaneously hypertensive rats (SHRs) in which it was reported that low activation of Csk by angiotensin II (Ang II) upregulates Src compared with normotensive Wistar-Kyoto rats (WKY), accelerating Ang II-induced growth in the vascular smooth muscle cells (VSMCs) of SHRs. ${ }^{24}$ A genetic analysis of crosses between Csk mutant mice and Src or Fyn mutant mice demonstrated that $S r c$, but not Fyn, is in part epistatic to $C s k$, wherein some of the defects in Csk-null embryos were rescued in $\mathrm{Src/Csk}$ double-knockout embryos. ${ }^{25}$

In contrast to the few studies on Csk, Src has been examined extensively with regard to blood pressure regulation, particularly in the RAAS in various tissues. As discussed, the activity of Src is important in Ang II-induced vasoconstriction of VSMCs. Ang II stimulates Src through angiotensin II type 1 receptor (AT1R) in rat VSMCs, ${ }^{26}$ and Ang II-induced intracellular $\mathrm{Ca}^{2+}$ mobilization and vascular contraction are abolished in $\mathrm{Src}^{-/-}$VSMCs and PP2-treated cells, respectively. ${ }^{27} \mathrm{~A}$ study in hypertensive rats that were induced by the 2-kidney 1-clip (2K1C) mechanism showed that $\mathrm{Src}$ activation was greater in the hypothalamus of $2 \mathrm{~K} 1 \mathrm{C}$ rats than in sham-operated rats, and that inhibition of Src negated the Ang II-induced increase in sympathetic nerve activity and blood pressure of $2 \mathrm{~K} 1 \mathrm{C}$, implicating Src in autonomic nerve regulation of blood pressure. ${ }^{28}$

Src activation is also required for Ang II-mediated functions in the kidney. In the renal proximal tubules, Src mediates Ang II-induced fluid reabsorption through the apical $\mathrm{Na}^{+} / \mathrm{H}^{+}$exchanger (NHE) and the basolateral $\mathrm{Na}^{+}-$ $\mathrm{HCO}_{3}{ }^{-}$cotransporter (NBC), and Csk overexpression inhibits the activation of both NHE and NBC. 29,30 Notably, Src modulates Ang II-induced aldosterone production in the adrenal gland. Inhibition of Src by PP2 increases CYP17A1 mRNA levels, slowing the synthesis of aldosterone in Ang II-stimulated H295R adrenal cells. ${ }^{31}$ Further, the binding of Ang II to AT1R enhances the activity of SRC and protein kinase C (PKC), which upregulates CYP11B2.32,33

Although many studies in animals, cells, and human populations have implicated $S R C$ and $C S K$ in blood pressure regulation, the mechanisms through which this occurs has not been determined. We have reported that knockdown and haploinsufficiency of Csk increase blood pressure through Src. Using the $C s k^{+/-}$mouse, we have established a regulatory pathway in which $C s k$ insufficiency induces the synthesis of aldosterone through the upregulation of Cyp11b2, resulting in high blood pressure.

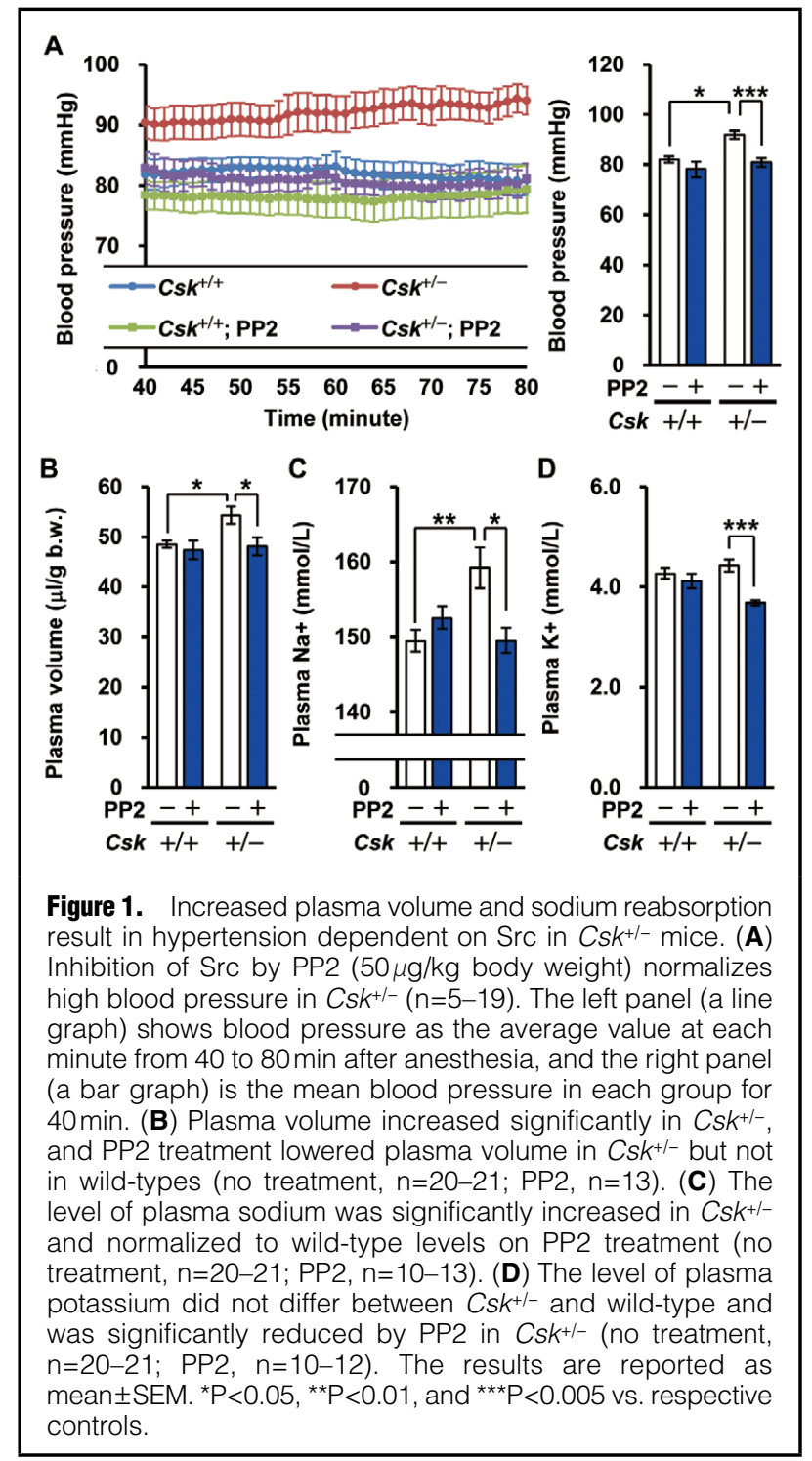

\section{Methods}

\section{Animal Research and Ethics Statement}

All mice were housed and handled in a pathogen-free facility at the College of Pharmacy, Kyung Hee University, as per the Guide for the Care and Use of Laboratory Animals, fully accredited by the Association for Assessment and Accreditation of Laboratory Animal Care. The mice were maintained on a 12-h light/dark cycle at constant temperature with free access to food (LabDiet 5L79, St. Louis, MO, USA) and water. Every effort was made to minimize the number of animals that was sacrificed and their suffering. Animals were anesthetized by intraperitoneal (i.p.) injection of tribromoethanol (Avertin, $18 \mathrm{~mL}$ of working solution per kg body weight), the working solution of which was diluted to $25 \mu \mathrm{g} / \mathrm{mL}$ in $0.9 \% \mathrm{NaCl}$ from the stock solution $(1 \mathrm{~g} / \mathrm{mL}$ 2,2,2-tribromoethanol dissolved in tertiary amyl alcohol), and euthanized by removal of the heart. The experiments were approved by the local committee for the Care and Use of Laboratory Animals, Kyung Hee University (license number: KHUASP(SE)-16-035). 
Table. ECG Parameters of $\mathrm{Csk}^{+/-}$and Wild-Types

\begin{tabular}{lccc} 
ECG trait & $\begin{array}{c}\mathbf{C s k}^{+/+} \\
(\mathbf{n}=\mathbf{1 0 )}\end{array}$ & $\begin{array}{c}\mathbf{C s k}^{+/-} \\
(\mathbf{n}=\mathbf{1 0})\end{array}$ & $\begin{array}{c}\text { P-value } \\
\text { (Mann-Whitney U-test) }\end{array}$ \\
Heart rate (beats/min) & $405.8 \pm 6.97$ & $392.8 \pm 7.00$ & 0.315 \\
PR interval (ms) & $58.0 \pm 1.35$ & $58.3 \pm 1.23$ & 0.661 \\
QRS duration (ms) & $12.5 \pm 0.37$ & $12.6 \pm 0.34$ & 0.796 \\
QTc interval (ms) & $70.3 \pm 5.44$ & $64.5 \pm 1.43$ & 0.971 \\
\hline
\end{tabular}

Results are expressed as mean \pm SEM. ECG, electrocardiogram.

\section{Mouse Genotyping}

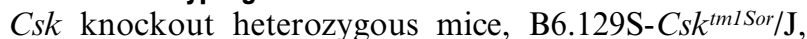
were purchased from Jackson Laboratory (Bar Harbor, Maine, USA). Heterozygous and wild-type homozygous pairs were mated, and the progeny was genotyped by polymerase chain reaction (PCR) with the primer set using the wild type (5'-CGCAGTCTACGAGGTGATGA-3'), the mutant (5'-CCTTCTATCGCCTTCTTGACG-3'), and the common reverse primer (5'-GGGCTCAGTTCAA GTTCAGG-3').

\section{Statistical Analysis}

The statistical analysis was performed using SPSS (IBM SPSS Statistics 22.0). The data were analyzed with the genotype and experimental conditions blinded. Two-group comparisons were performed by using the Mann-Whitney $\mathrm{U}$-test, because the U-test is generally considered to be more powerful than the t-test. ${ }^{34}$ The parenthetical values in the legend indicate the number of mice that was used for each group. The results are reported as mean \pm SEM. Differences with $\mathrm{P}<0.05$ were considered statistically significant. ${ }^{*} \mathrm{P}<0.05,{ }^{*} * \mathrm{P}<0.01$, and $* * * \mathrm{P}<0.005$ vs. respective controls.

Further details regarding the methods used, including blood pressure measurement, reagents, electrocardiogram, plasma volume determination, plasma and urine analyses, quantitative real-time PCR, western blotting, immunohistochemistry and immunofluorescence, are described in the Supplementary File 1.

\section{Results}

\section{Increased Plasma Volume and Sodium Reabsorption Cause Hypertension Through Src in $\boldsymbol{C s k}^{+/-}$Mice}

Csk modulates blood pressure through Src activation. ${ }^{18}$ Here, we confirmed that the administration of PP2 $(50 \mu \mathrm{g} / \mathrm{kg}$ body weight), a Src inhibitor, significantly reduced blood pressure only in $C s k^{+/-}$mice, without a significant effect in wild-type mice $\left(C s k^{+/+}\right)$(Figure 1A).

Major components that regulate blood pressure involve

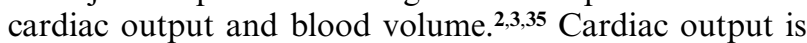
affected by heart rate and stroke volume.,36 To determine the contribution of cardiac output, we measured the heart rate by electrocardiogram (ECG) in $C s k^{+/-}$and wild-types. There was no significant change in ECG parameters, including heart rate, PR interval, QRS duration, and QTc interval (Table).

Then, we measured plasma volume using Evans blue dye in both groups. ${ }^{37}$ Plasma volume rose significantly in $\mathrm{Csk}^{+/-}$ compared with wild-types (Figure 1B). Treatment with PP2 negated this increase in $C s k^{+-}$but did not significantly alter levels in wild-type animals, which is consistent with its effect on blood pressure (Figure 1B). These results suggest that elevations in plasma volume underlie hypertension in $\mathrm{Csk}^{+/-}$and are attributable to Csk/Src signaling.

To determine whether the increase in plasma volume was caused by ion reabsorption, we measured the amounts of plasma $\mathrm{Na}^{+}$(sodium) and $\mathrm{K}^{+}$(potassium) using ionselective electrodes (ISEs). Plasma $\mathrm{Na}^{+}$concentrations rose significantly in $C s k^{+/-}$compared with wild-type mice and declined on treatment with PP2 (Figure 1C). Plasma $\mathrm{K}^{+}$ concentrations did not differ between $C s k^{+/-}$and wild-type mice and were decreased significantly with PP2 in $C s k^{+/-}$ (Figure 1D). The consistent changes in plasma volume and $\mathrm{Na}^{+}$levels suggest that the alteration in plasma volume is attributable to increased $\mathrm{Na}^{+}$reabsorption due to Csk insufficiency.

\section{Increased Plasma Aldosterone Causes Hypertension in Csk+/-}

Because plasma volume and $\mathrm{Na}^{+}$levels are regulated directly by aldosterone, we measured the aldosterone content in mouse plasma and urine using an enzyme immunoassay (EIA) kit. Plasma aldosterone levels were significantly higher in $C s k^{+/-}$vs. wild-types (Figure 2A), whereas urine aldosterone levels did not differ between the groups (Figure 2B), indicating that aldosterone is a significant factor of hypertension in $C s k^{+/-}$mice. After PP2 treatment, plasma aldosterone levels failed to decrease in either group (Figure 2A), but urine aldosterone fell significantly by $45 \%$ in $C s k^{+-}$(Figure 2B).

To examine the function of aldosterone in regulating blood pressure in $\mathrm{Cs} \mathrm{K}^{+-}$, we measured the effects of spironolactone, a mineralocorticoid receptor (MR) antagonist, via i.p. injection. Spironolactone decreased blood pressure similarly in $C s k^{+/-}$and wild-types (Figure 2C), suggesting MR-dependent hypertension.

To determine whether the increase in aldosterone influenced the expression of ion reabsorption-related molecules in the kidney, we performed western blot to estimate the levels of serum- and glucocorticoid-regulated kinase 1 (Sgk1) and the kidney channels: ROMK, a renal outer medullary potassium channel; $\mathrm{ENaC} \alpha / \beta$, an epithelial sodium channel; and NKA $\alpha$, the $\mathrm{Na}^{+} / \mathrm{K}^{+}$-ATPase $\alpha$ subunit. ROMK co-localizes with Src in the kidney, and the stimulation of Src directly and indirectly induces endocytosis of ROMK, leading to the conservation of potassium. ${ }^{38}$ $\mathrm{ENaC} \alpha / \beta$ and NKA $\alpha$ are the 2 main effectors of sodium reabsorption in the cortical collecting duct of the kidney, and their activities and levels change in response to aldosterone. ${ }^{39,40} \mathrm{Sgk} 1$ upregulates rapidly due to aldosterone in cortical collecting duct cells, increasing the number of active $\mathrm{ENaC} \alpha / \beta \mathrm{s}^{41}$

In our results, the level of ROMK decreased significantly in the kidney of $\mathrm{Csk}^{+/-}$, which is consistent with several reports that have suggested a direct function of Src in 

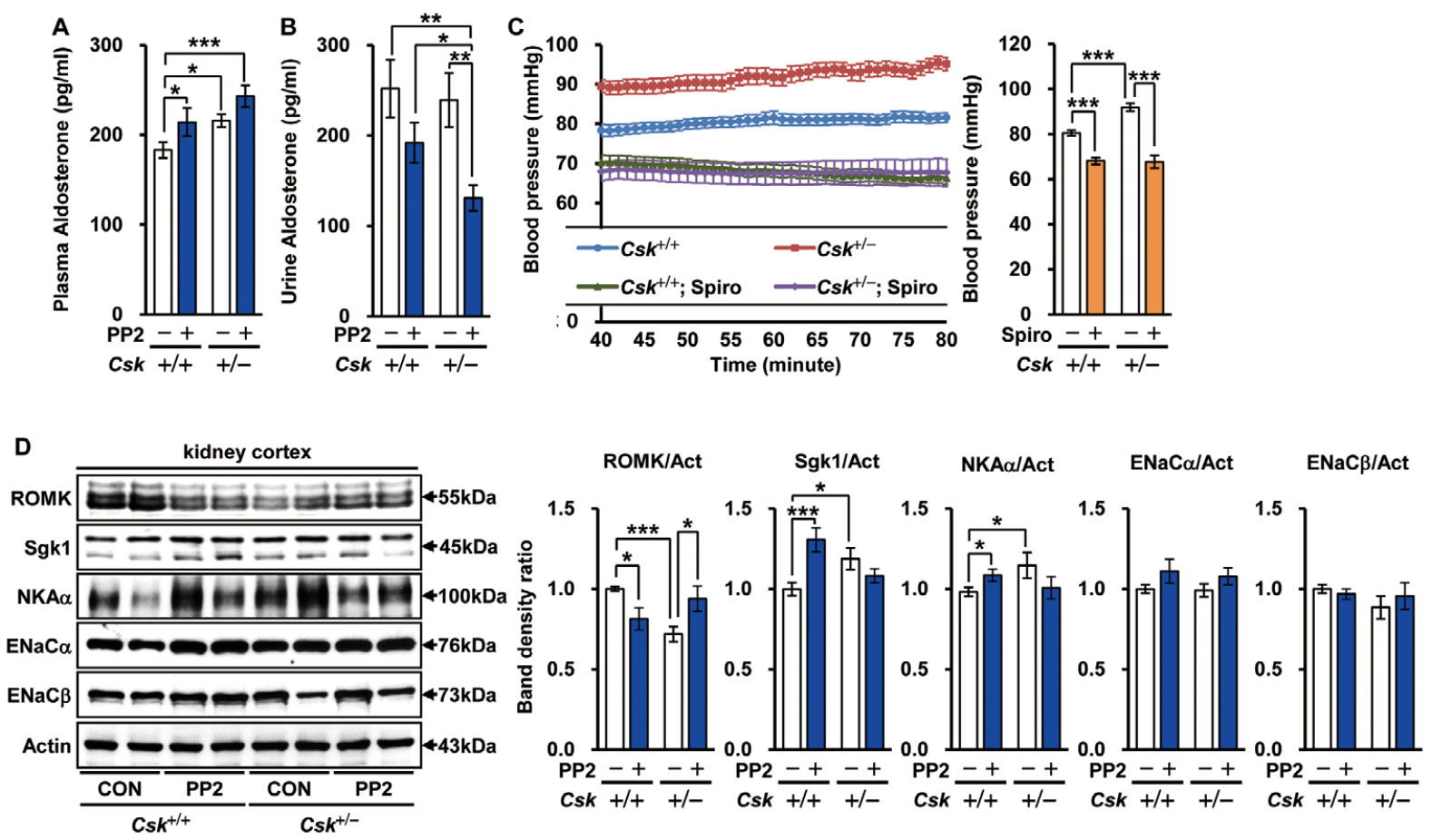

Figure 2. Increased aldosterone leads to hypertension in $\mathrm{Csk}^{+/-}$. (A) Plasma aldosterone was significantly higher in $\mathrm{Csk}^{+/-}$than in wild-types and increased further by PP2 treatment in both groups (no treatment, $n=40$; PP2, $n=19-21$ ). (B) Urine aldosterone was unchanged between $\mathrm{Csk}^{+/-}$and wild-types but decreased significantly in $\mathrm{Csk}^{+/-}$on PP2 treatment (no treatment, $\mathrm{n}=22-23$; PP2, $\mathrm{n}=20-27)$. (C) Spironolactone (Spiro), an MR inhibitor, was injected i.p. into mice (50 mg/kg) $2 \mathrm{~h}$ before measurement. Inhibition of MR lowered blood pressure in Csk ${ }^{+/-}$and wild-types (no treatment, $n=12-18$; spironolactone, $n=7-11$ ). (D) Representative western blots of the kidney cortex proteins are shown in the left panel, and the graphs of the relative band density of each protein are presented in the right panels, as normalized to actin. The ROMK channel was significantly decreased in Csk ${ }^{+/-}$, and PP2 treatment normalized its level $(n=14-18)$. The Sgk1 and NKAa channel proteins increased significantly in $C s k^{+l-}$ and were partially normalized by PP2 (Sgk1, $\mathrm{n}=16-18 ; \mathrm{NKA} a, \mathrm{n}=13-21)$. $\mathrm{ENaC} a$ and $\beta$ channels were unchanged between groups $(\mathrm{ENaC} a, \mathrm{n}=12-16 ; \mathrm{ENaC} \beta$, $n=4-10)$. The results are reported as mean \pm SEM. ${ }^{*} P<0.05$, ${ }^{*} P<0.01$, and ${ }^{* *} P<0.005$ vs. respective controls.

degrading ROMK in the kidney (Figures 2D,S1). ${ }^{38}$ The amounts of Sgk1 and NKA $\alpha$ rose significantly in $C s k^{+/-}$, whereas the total amounts of $\mathrm{ENaC} \alpha / \beta$ were unchanged (Figure 2D). PP2 partially normalized the increases in Sgk1 and NKA $\alpha$ (Figure 2D). These results suggest that aldosterone facilitates transcellular movement of sodium by upregulating Sgk1 and NKA $\alpha$ in $C_{s k}{ }^{+/-}$.

\section{Altered Expression of Steroidogenic Enzymes Increases Aldosterone Production in the Adrenal Gland of $\mathbf{C s k}^{+/-}$}

To examine whether a deficiency in $C s k$ affects the synthetic pathway of aldosterone, we measured the mRNA levels of 5 cytochrome P450 family enzymes that participate in steroidogenic pathways in the adrenal gland of mice: StAR, a steroidogenic acute regulatory protein; Cyp 1 lal, a cholesterol side-chain cleavage enzyme; $H s d 3 b 1,3 \beta$-hydroxysteroid dehydrogenase type 1 (the murine ortholog of human $H S D 3 B 2)$; Cyp11b1, 11 $\beta$-hydroxylase; and Cyp11b2, aldosterone synthase (Figure 3C).

The mRNA levels of StAR, which transports cholesterol into the mitochondria, did not differ between $\mathrm{Csk}^{+/-}$and wild-types but increased on PP2 treatment (Figure 3A). Cypllal declined significantly in $C s k^{+/-}$compared with wild-types and returned to wild-type levels after PP2 treatment (Figure 3A), implying that the overall pool of precursors that enters the steroidogenic pathways is constrained in $C s k^{+/-}$. The effects of PP2 on StAR and Cypllal expression are consistent with a previous report in which the inhibition of Src increased mRNA levels of StAR and CYP11A1.42

$H s d 3 b 1$ was unchanged in $C s k^{+/-}$and after PP2 treatment (Figure 3A). The mRNA level of Cyp1 1b1, which mediates the last step in corticosterone synthesis, increased in $\mathrm{Csk}^{+/-}$ compared with wild-types, but was unaffected by PP2 (Figure 3A). Cyp11b2, the last enzyme in the synthesis of aldosterone, rose significantly in $C_{s k^{+/-}}$vs. wild-types and returned to basal levels with PP2 (Figure 3A).

To measure the changes in the aldosterone synthase levels in the adrenal gland, a western blot was performed using an antibody against Cyp11b2. Active Src increased significantly in $\mathrm{Csk}^{+/-}$, whereas inactive Src declined (Figure 3B). The activation of Src was mitigated to wild-type levels by PP2 but did not normalize completely (Figure 3B). Csk remained significantly low in $\mathrm{Csk}^{+/}$, regardless of PP2 treatment (Figure 3B). Consistent with their mRNA levels, Cyp1 $1 \mathrm{~b} 2$ increased significantly in $\mathrm{Csk}^{+/-}$, and normalized to the wild-type level with PP2 treatment (Figure 3B). 

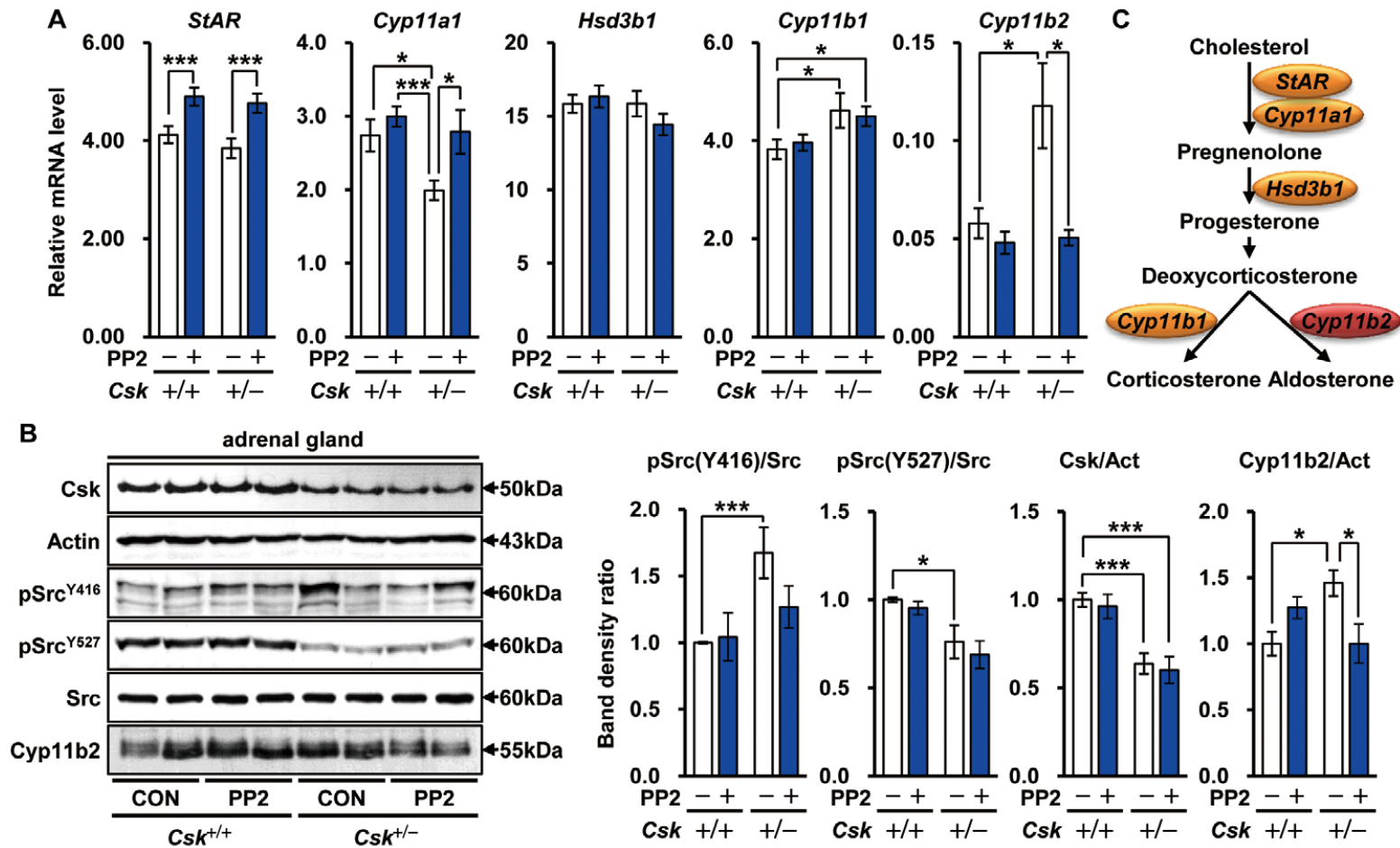

Figure 3. Altered expression of steroidogenic enzymes induces aldosterone production in the adrenal glands of $C s k^{+/-}$. (A) Total RNA from adrenal glands was analyzed by qRT-PCR. Data are presented as the average value of the relative mRNA levels of each group, normalized to Gapdh mRNA $(n=12-27)$. (A) StAR mRNA did not differ between Csk+/- and wild-types and increased on PP2 treatment. Cyp 11a1 transcripts fell in Csk+-- and were normalized by PP2. Hsd3b1 mRNA was unchanged between groups. Cyp $11 \mathrm{~b} 1 \mathrm{mRNA}$ rose in $\mathrm{Csk}^{+/-}$but was unchanged by PP2. The level of Cyp11b2 mRNA increased in Csk ${ }^{+-}$and returned to wild-type levels by PP2. (B) Representative western blots of adrenal gland proteins and the graphs of the relative band density of each protein are presented in the left and right panel, respectively. Phosphorylated proteins are normalized to total proteins, and total proteins to actin. Phosphorylated Src ${ }^{Y 416}$ (active) increased significantly in $C_{s k}^{+/-}(n=4-6)$, whereas phosphorylated $\mathrm{Src}^{Y 527}$ (inactive) decreased $(n=8-10)$. Activation of Src was partially normalized by PP2. Csk remained low in Csk ${ }^{+/-}$, regardless of PP2 treatment $(n=8)$. The amount of Cyp11b2 increased significantly in $C s k^{+/-}(n=4)$, and reverted to wild-type levels by PP2 $(n=4)$. The results are reported as mean \pm SEM. ${ }^{*} \mathrm{P}<0.05$, ${ }^{* *} \mathrm{P}<0.01$, and ${ }^{* \star *} \mathrm{P}<0.005$ vs. respective controls. (C) Diagram of steroidogenic enzymes involved in aldosterone production of mice. Cholesterol is transferred into the mitochondria by StAR, which is a rate-limiting step in the production of steroid hormones, and is cleaved by Cyp11a1, resulting in pregnenolone. Consequently, pregnenolone is converted to progesterone by Hsd3b1. Cyp11b1 is the corticosterone synthesis enzyme in the zona fasciculata/zona reticularis (ZF/ZR), and Cyp11b2 is the aldosterone synthesis enzyme, expressed primarily in the zona glomerulosa (ZG).

\section{Csk Abounds in the Zona Glomerulosa of the Mouse Adrenal Gland}

To study the expression of Csk in the adrenal gland, we performed an immunohistochemical analysis using an antibody against Csk. The mammalian adrenal gland cortex comprises 3 concentric steroidogenic zones in which the 3 principal types of steroid hormones are produced: mineralocorticoids, such as aldosterone, in the zona glomerulosa (ZG, the outermost zone of the adrenal); glucocorticoids, such as cortisol and corticosterone, in the zona fasciculata ( $\mathrm{ZF}$, the middle zone between the glomerulosa and reticularis); and androgens in the zona reticularis (ZR, the innermost zone). . $3,44^{-4}$

Csk was expressed in the mouse adrenal gland at higher levels in the $\mathrm{ZG}$ than in the $\mathrm{ZF}$ and $\mathrm{ZR}$, as shown by densitometry of the positive-stained areas (Figure 4A). The zone-specific pattern of Csk expression was then confirmed by immunofluorescence. Csk was clearly visible as red fluorescence, which was strong in the ZG and moderate in the ZR, but absent from the ZF (Figure 4C). In contrast, Src was ubiquitously expressed throughout all zones (Figure 4B).

These results suggest that a deficiency in Csk influences the synthetic pathway of aldosterone by altering Cyp $11 \mathrm{~b} 2$ expression with zonal specificity, as illustrated in Figure 4D.

\section{Discussion}

Our data have identified Csk as a key modulator of blood pressure, demonstrating that a deficiency in Csk increases plasma volume and sodium reabsorption through greater synthesis of aldosterone in the adrenal gland, ultimately resulting in high blood pressure.

Our 2 principal findings are as follows. Csk regulates blood volume, which is among the major factors that affect blood pressure, such as cardiac output (heart ratexstroke volume), and peripheral vessel resistance. A contribution of heart rate to blood pressure has been ruled out, because the electrocardiogram of $\mathrm{Csk}^{+/-}$showed no change in heart rate. The intrinsic resistance of blood vessels was not assessed in our study. The function of Csk in the vasculature 
has been presumed to contribute to the generation of hypertension, based on reports in Csk-null embryos and VSMCs of SHRs.23,24,45 Thus, to further examine the function of Csk in the vasculature, it might be more appropriate to study the in vitro vascular reactivity of resistant arteries by using a VSMC-specific $C s k$ knockout mouse. In addition to the vasculature, the intrinsic function of $C s k$ in other tissues, such as the kidney and brain, must be examined in a mouse with tissue-specific deficiency of $C s k$ to rule out the effects of variations in aldosterone.

Our second major finding is the regulatory function of Csk in aldosterone formation in the adrenal gland. Our results demonstrate that the synthetic pathway of aldosterone is enhanced in the adrenal gland of $C s k^{+-}$, as depicted in Figure 4D. Plasma aldosterone rises through greater Cyp11b2 expression in the adrenal gland and exerts its effects on Sgk1 and the NKA $\alpha$ channel in the kidney, increasing sodium reabsorption.

In the kidney, the amount of ROMK channels decreased, but the effect of this reduction on hypertension remained unknown, because plasma potassium levels were unchanged in the kidney of $\mathrm{Csk}^{+/-}$. The increase in Sgk1 suggests that higher aldosterone levels act on kidney channels through the induction of Sgk 1 in $\mathrm{Cs}^{+/-}$. Of the 2 main effectors of sodium reabsorption, NKAs increase in activity and number in response to aldosterone, whereas $\mathrm{ENaCs}$ undergo early activation but experience a slow rise in number. ${ }^{39,40}$ In our results, the total amount of $\mathrm{ENaC} \alpha / \beta$ did not increase in $\mathrm{Csk}^{+/-}$, implying that aldosterone-induced Sgk1 affects only the activity of $\mathrm{ENaCs}$, not their expression level. ${ }^{41}$ The upregulation of NKA $\alpha$ suggests that transcellular movement of sodium is facilitated by aldosteroneinduced NKAs in $C s k^{+-} \cdot{ }^{40}$ Treatment with PP2 partially reversed the increase in Sgk1 and NKA $\alpha$ to wild-type levels, likely due to a delayed effect throughout the synthesis of steroidogenic enzymes and the degradation of accumulated proteins.

The regulation of CYP11B2 by SRC has been supported by several reports. SRC induces members of the nuclear receptor superfamily/nerve growth factor-induced (NGFIB) family of transcription factors, which are required for the generation of $C Y P 11 B 2$ transcripts..$^{33,46}$ Recent studies suggest that SRC-induced protein kinase $\mathrm{D}(\mathrm{PKD} / \mathrm{PKC} \mu)$ mediates aldosterone production and upregulates $C Y P 11 B 2$ in the ZG. Constitutively active PKD constructs upregulate CYP11B2 in human adrenocortical cells, and treatment with PP2 and Src-I, selective Src family kinase inhibitors, represses the activation of $\mathrm{PKD}$, consequently impeding Ang II-induced aldosterone production in primary bovine adrenal glomerulosa cells. ${ }^{47,48}$ Once activated, PKD phosphorylates activating transcription factor (ATF)/cAMP response element binding protein (CREB) members, which are also important for $C Y P 11 B 2$ transcription. ${ }^{49}$ Notably, we found that Csk was enriched in the ZG, whereas Src is expressed throughout the adrenal cortex, implying that the regulation of aldosterone production by Csk may converge in the ZG. As with steroidogenic enzymes, the adrenal gland exhibits a zone-specific expression pattern of AT1R in the $Z \mathrm{ZG}^{50}$ indicating that the negative regulation of Cyp 11 b2 by Csk is a safeguard that maintains the normal range of aldosterone production in Ang II-controlled situations.

Our study demonstrates a novel pathway of blood pressure regulation whereby Csk influences aldosterone production, therefore modulating sodium reabsorption

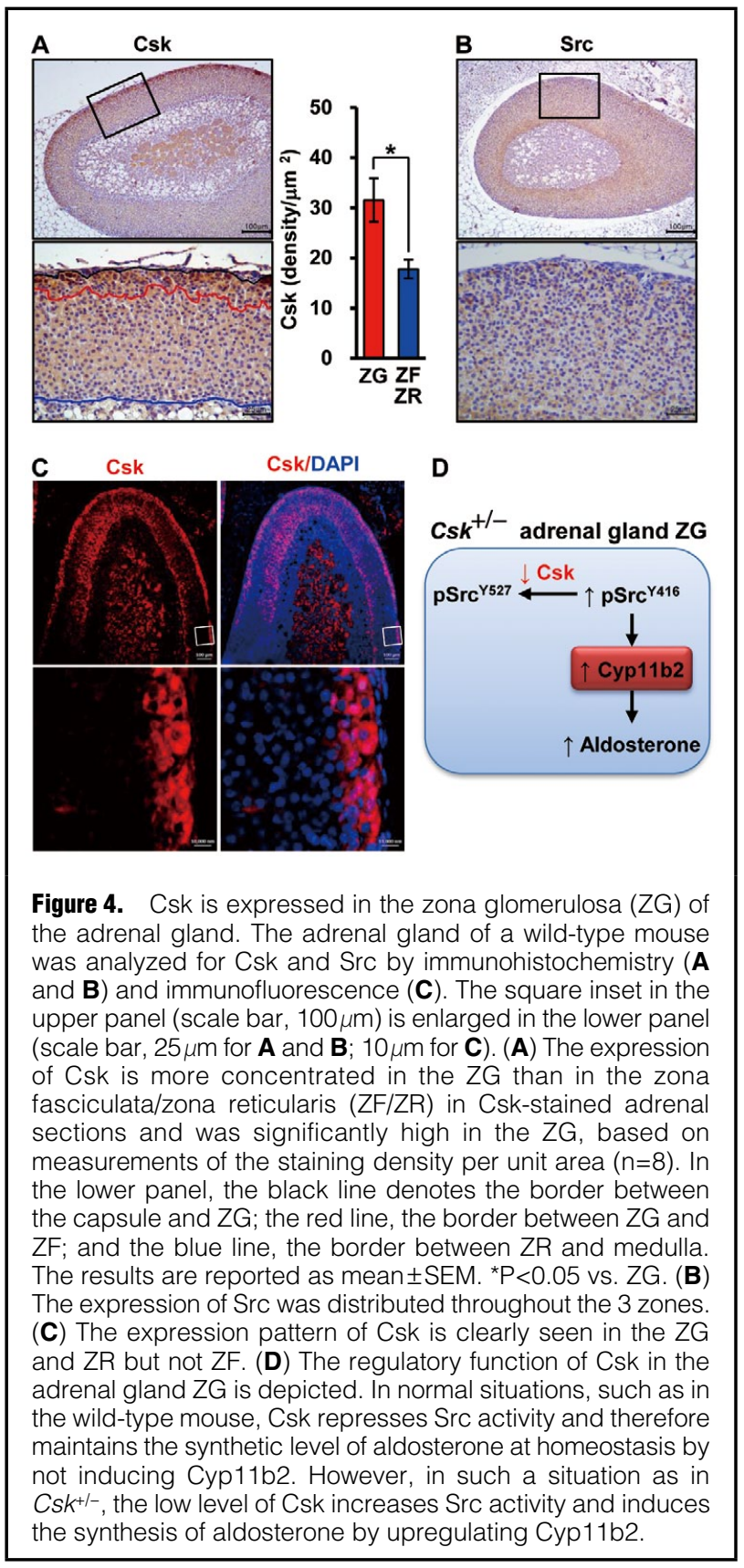

and plasma volume. Thus, our findings increase our understanding of the mechanisms of aldosterone production in the adrenal gland and aldosterone-inducible hypertension.

\section{Study Limitations}

We have used a mouse model with global Csk insufficiency, rather than a mouse with an adrenal gland-specific Csk deficiency. As Csk and Src were not only expressed in various tissues including vasculature, kidney, and brain, but their regional functions were also known to contribute to the generation of hypertension; our study should not be overestimated beyond a role of Csk in the adrenal gland. Future research is warranted for the important roles of Csk in diverse tissues.

Another weakness in our study was that plasma aldo- 
sterone levels rose in $\mathrm{Cs}^{+/-}$than wild-types, but further increased by PP2 treatment (Figure 2A). We assumed that it might be somewhat explained by the lowered urinary excretion of aldosterone after PP2 treatment (Figure 2B), although the change in urinary excretion was unexplainable in this study. It might be helpful to distinguish the major metabolites (dihydroaldosterone and tetrahydroaldosterone) of aldosterone in mice to understand the effect of PP2 treatment, which was not possible by using an EIA kit.

\section{Acknowledgments}

We thank Mr. Won-Jae Jung for help with the sodium and potassium analyses (Seoul Medical Science Institute, Kyung Ki Do, Korea).

\section{Grants}

This work was supported by the Basic Science Research Program through a National Research Foundation of Korea (NRF) grant (NRF-2014R1A2A2A01005277).

\section{References}

1. Padmanabhan S, Newton-Cheh C, Dominiczak AF. Genetic basis of blood pressure and hypertension. Trends Genet 2012; 28: 397-408.

2. Lifton RP, Gharavi AG, Geller DS. Molecular mechanisms of human hypertension. Cell 2001; 104: 545-556.

3. Padmanabhan S, Caulfield M, Dominiczak AF. Genetic and molecular aspects of hypertension. Circ Res 2015; 116: 937-959.

4. Hoffmann TJ, Ehret GB, Nandakumar P, Ranatunga D, Schaefer C, Kwok PY, et al. Genome-wide association analyses using electronic health records identify new loci influencing blood pressure variation. Nat Genet 2017; 49: 54-64.

5. Surendran P, Drenos F, Young R, Warren H, Cook JP, Manning $\mathrm{AK}$, et al. Trans-ancestry meta-analyses identify rare and common variants associated with blood pressure and hypertension. Nat Genet 2016; 48: 1151-1161.

6. Liu C, Kraja AT, Smith JA, Brody JA, Franceschini N, Bis JC, et al. Meta-analysis identifies common and rare variants influencing blood pressure and overlapping with metabolic trait loci. Nat Genet 2016; 48: 1162-1170.

7. Ehret GB, Ferreira T, Chasman DI, Jackson AU, Schmidt EM, Johnson T, et al. The genetics of blood pressure regulation and its target organs from association studies in 342,415 individuals. Nat Genet 2016; 48: 1171-1184.

8. Padmanabhan S, Melander O, Johnson T, Di Blasio AM, Lee WK, Gentilini D, et al. Genome-wide association study of blood pressure extremes identifies variant near UMOD associated with hypertension. PLoS Genet 2010; 6: e1001177.

9. Salvi E, Kutalik Z, Glorioso N, Benaglio P, Frau F, Kuznetsova $\mathrm{T}$, et al. Genomewide association study using a high-density single nucleotide polymorphism array and case-control design identifies a novel essential hypertension susceptibility locus in the promoter region of endothelial NO synthase. Hypertension 2012; 59: $248-255$.

10. Salvi E, Kuznetsova T, Thijs L, Lupoli S, Stolarz-Skrzypek K, D'Avila F, et al. Target sequencing, cell experiments, and a population study establish endothelial nitric oxide synthase (eNOS) gene as hypertension susceptibility gene. Hypertension 2013; 62: 844-852.

11. Ehret GB, Munroe PB, Rice KM, Bochud M, Johnson AD, Chasman DI, et al. Genetic variants in novel pathways influence blood pressure and cardiovascular disease risk. Nature 2011; 478: $103-109$.

12. Arora P, Wu C, Khan AM, Bloch DB, Davis-Dusenbery BN, Ghorbani A, et al. Atrial natriuretic peptide is negatively regulated by microRNA-425. J Clin Invest 2013; 123: 3378-3382.

13. Cho YS, Go MJ, Kim YJ, Heo JY, Oh JH, Ban HJ, et al. A large-scale genome-wide association study of Asian populations uncovers genetic factors influencing eight quantitative traits. Nat Genet 2009; 41: 527-534.

14. Shin YB, Lim JE, Ji SM, Lee HJ, Park SY, Hong KW, et al. Silencing of Atp2b1 increases blood pressure through vasoconstriction. J Hypertens 2013; 31: 1575-1583.

15. Newton-Cheh C, Johnson T, Gateva V, Tobin MD, Bochud M, Coin L, et al. Genome-wide association study identifies eight loci associated with blood pressure. Nat Genet 2009; 41: 666-676.
16. Kato N, Takeuchi F, Tabara Y, Kelly TN, Go MJ, Sim X, et al. Meta-analysis of genome-wide association studies identifies common variants associated with blood pressure variation in east Asians. Nat Genet 2011; 43: 531-538.

17. Takeuchi $\mathrm{F}$, Isono M, Katsuya $\mathrm{T}$, Yamamoto K, Yokota M, Sugiyama T, et al. Blood pressure and hypertension are associated with 7 loci in the Japanese population. Circulation 2010; 121: $2302-2309$.

18. Lee HJ, Kang JO, Kim SM, Ji SM, Park SY, Kim ME, et al. Gene silencing and haploinsufficiency of Csk increase blood pressure. PLoS One 2016; 11: 0146841.

19. Nada S, Okada M, MacAuley A, Cooper JA, Nakagawa H. Cloning of a complementary DNA for a protein-tyrosine kinase that specifically phosphorylates a negative regulatory site of p60c-src. Nature 1991; 351: 69-72.

20. Okada M, Nada S, Yamanashi Y, Yamamoto T, Nakagawa H. CSK: A protein-tyrosine kinase involved in regulation of src family kinases. J Biol Chem 1991; 266: 24249-24252.

21. Nada S, Yagi T, Takeda H, Tokunaga T, Nakagawa H, Ikawa $\mathrm{Y}$, et al. Constitutive activation of Src family kinases in mouse embryos that lack Csk. Cell 1993; 73: 1125-1135.

22. Okada M. Regulation of the SRC family kinases by Csk. Int $J$ Biol Sci 2012; 8: 1385-1397.

23. Duan LJ, Imamoto A, Fong GH. Dual roles of the C-terminal Src kinase (Csk) during developmental vascularization. Blood 2004; 103: 1370-1372.

24. Touyz RM, Wu XH, He G, Salomon S, Schiffrin EL. Increased angiotensin II-mediated Src signaling via epidermal growth factor receptor transactivation is associated with decreased C-terminal Src kinase activity in vascular smooth muscle cells from spontaneously hypertensive rats. Hypertension 2002; 39: 479-485.

25. Thomas SM, Soriano P, Imamoto A. Specific and redundant roles of Src and Fyn in organizing the cytoskeleton. Nature 1995; 376: $267-271$

26. Ishida M, Marrero MB, Schieffer B, Ishida T, Bernstein KE, Berk BC. Angiotensin II activates pp60c-src in vascular smooth muscle cells. Circ Res 1995; 77: 1053-1059.

27. Touyz RM, Wu XH, He G, Park JB, Chen X, Vacher J, et al. Role of c-Src in the regulation of vascular contraction and $\mathrm{Ca} 2+$ signaling by angiotensin II in human vascular smooth muscle cells. J Hypertens 2001; 19: 441-449.

28. Han Y, Yuan N, Zhang SJ, Gao J, Shi Z, Zhou YB, et al. c-Src in paraventricular nucleus modulates sympathetic activity and cardiac sympathetic afferent reflex in renovascular hypertensive rats. Pflugers Arch 2011; 461: 437-446.

29. Robey RB, Ruiz OS, Espiritu DJ, Ibanez VC, Kear FT, Noboa $\mathrm{OA}$, et al. Angiotensin II stimulation of renal epithelial cell $\mathrm{Na} /$ HCO3 cotransport activity: A central role for Src family kinase/ classic MAPK pathway coupling. J Membr Biol 2002; 187: 135145.

30. Yamaji Y, Amemiya M, Cano A, Preisig PA, Miller RT, Moe $\mathrm{OW}$, et al. Overexpression of csk inhibits acid-induced activation of NHE-3. Proc Natl Acad Sci U S A 1995; 92: 6274-6278.

31. Sirianni R, Carr BR, Pezzi V, Rainey WE. A role for src tyrosine kinase in regulating adrenal aldosterone production. $J \mathrm{Mol}$ Endocrinol 2001; 26: 207-215.

32. Bassett MH, Suzuki T, Sasano H, White PC, Rainey WE. The orphan nuclear receptors NURR 1 and NGFIB regulate adrenal aldosterone production. Mol Endocrinol 2004; 18: 279-290.

33. Nogueira EF, Xing Y, Morris CA, Rainey WE. Role of angiotensin II-induced rapid response genes in the regulation of enzymes needed for aldosterone synthesis. J Mol Endocrinol 2009; 42: 319-330.

34. Fay MP, Proschan MA. Wilcoxon-Mann-Whitney or t-test? On assumptions for hypothesis tests and multiple interpretations of decision rules. Stat Surv 2010; 4: 1-39.

35. Freis ED. Salt, volume and the prevention of hypertension. Circulation 1976; 53: 589-595.

36. Isbister JP. Physiology and pathophysiology of blood volume regulation. Transfus Sci 1997; 18: 409-423.

37. Kaufman S. Role of spleen in ANF-induced reduction in plasma volume. Can J Physiol Pharmacol 1992; 70: 1104-1108.

38. van der Lubbe N, Zietse R, Hoorn EJ. Effects of angiotensin II on kinase-mediated sodium and potassium transport in the distal nephron. Curr Opin Nephrol Hypertens 2013; 22: 120-126.

39. Petty KJ, Kokko JP, Marver D. Secondary effect of aldosterone on Na-KATPase activity in the rabbit cortical collecting tubule. J Clin Invest 1981; 68: 1514-1521.

40. Salyer SA, Parks J, Barati MT, Lederer ED, Clark BJ, Klein JD, et al. Aldosterone regulates $\mathrm{Na}(+), \mathrm{K}(+)$ ATPase activity in 
human renal proximal tubule cells through mineralocorticoid receptor. Biochim Biophys Acta 2013; 1833: 2143-2152.

41. Chen SY, Bhargava A, Mastroberardino L, Meijer OC, Wang J, Buse $\mathrm{P}$, et al. Epithelial sodium channel regulated by aldosteroneinduced protein sgk. Proc Natl Acad Sci U S A 1999; 96: 2514 2519.

42. Sirianni R, Carr BR, Ando S, Rainey WE. Inhibition of Src tyrosine kinase stimulates adrenal androgen production. $J \mathrm{Mol}$ Endocrinol 2003; 30: 287-299.

43. Ishimura K, Fujita H. Light and electron microscopic immunohistochemistry of the localization of adrenal steroidogenic enzymes. Microsc Res Tech 1997; 36: 445-453.

44. Gomez-Sanchez CE, Qi X, Velarde-Miranda C, Plonczynski MW, Parker CR, Rainey W, et al. Development of monoclonal antibodies against human CYP11B1 and CYP11B2. Mol Cell Endocrinol 2014; 383: 111-117.

45. Qin B, Zhou J. Src family kinases (SFK) mediate angiotensin II-induced myosin light chain phosphorylation and hypertension. PLoS One 2015; 10: e0127891.

46. Hattangady NG, Olala LO, Bollag WB, Rainey WE. Acute and chronic regulation of aldosterone production. Mol Cell Endocrinol 2012; 350: 151-162.

47. Romero DG, Welsh BL, Gomez-Sanchez EP, Yanes LL, Rilli S, Gomez-Sanchez CE. Angiotensin II-mediated protein kinase D activation stimulates aldosterone and cortisol secretion in H295R human adrenocortical cells. Endocrinology 2006; 147: 6046-6055.
48. Olala LO, Shapiro BA, Merchen TC, Wynn JJ, Bollag WB. Protein kinase $\mathrm{C}$ and Src family kinases mediate angiotensin IIinduced protein kinase D activation and acute aldosterone production. Mol Cell Endocrinol 2014; 392: 173-181.

49. Olala LO, Choudhary V, Johnson MH, Bollag WB. Angiotensin II-induced protein kinase D activates the ATF/CREB family of transcription factors and promotes StAR mRNA expression. Endocrinology 2014; 155: 2524-2533.

50. Breault L, Lehoux JG, Gallo-Payet N. Angiotensin II receptors in the human adrenal gland. Endocr Res 1996; 22: 355-361.

\section{Supplementary Files}

Supplementary File 1

\section{Supplementary Methods}

Figure S1. Src activation is dependent on Csk and inhibited by PP2 treatment in the kidney cortex.

Table S1. Primers for quantitative real-time polymerase chain reaction

Table S2. Lists of antibodies used for WB, IHC, and IF

Please find supplementary file(s);

http://dx.doi.org/10.1253/circj.CJ-17-0080 